\title{
A comparative study of the proliferation and osteogenic differentiation of human periodontal ligament cells cultured on $\beta$-TCP ceramics and demineralized bone matrix with or without osteogenic inducers in vitro
}

\author{
SHAOFENG AN ${ }^{1 *}$, YAN GAO $^{1 *}$, XIANGYA HUANG ${ }^{1}$, JUNQI LING $^{1}$, ZHAOHUI LIU ${ }^{1}$ and YIN XIAO ${ }^{2}$ \\ ${ }^{1}$ Department of Operative Dentistry and Endodontics, Guanghua School of Stomatology, Hospital of Stomatology, \\ Sun Yat-sen University; Guangdong Provincial Key Laboratory of Stomatology, Guangzhou, Guangdong 510055, P.R. China; \\ ${ }^{2}$ Institute of Health and Biomedical Innovation, Queensland University of Technology, Brisbane, QLD 4059, Australia
}

Received August 31, 2014; Accepted February 27, 2015

DOI: 10.3892/ijmm.2015.2122

\begin{abstract}
The repair of bone defects that result from periodontal diseases remains a clinical challenge for periodontal therapy. $\beta$-tricalcium phosphate $(\beta$-TCP) ceramics are biodegradable inorganic bone substitutes with inorganic components that are similar to those of bone. Demineralized bone matrix (DBM) is an acid-extracted organic matrix derived from bone sources that consists of the collagen and matrix proteins of bone. A few studies have documented the effects of DBM on the proliferation and osteogenic differentiation of human periodontal ligament cells (hPDLCs). The aim of the present study was to investigate the effects of inorganic and organic elements of bone on the proliferation and osteogenic differentiation of hPDLCs using three-dimensional porous $\beta$-TCP ceramics and DBM with or without osteogenic inducers. Primary hPDLCs were isolated from human periodontal ligaments. The proliferation of the hPDLCs on the scaffolds in the growth culture medium was examined using a Cell-Counting kit-8 (CCK-8) and scanning electron microscopy (SEM). Alkaline phosphatase (ALP)
\end{abstract}

Correspondence to: Professor Junqi Ling, Department of Operative Dentistry and Endodontics, Guanghua School of Stomatology, Hospital of Stomatology, Sun Yat-sen University; Guangdong Provincial Key Laboratory of Stomatology, 56 Ling Yuan Xi Road, Guangzhou, Guangdong 510055, P.R. China

E-mail: lingjq@mail.sysu.edu.cn

Professor Yin Xiao, Institute of Health and Biomedical Innovation, Queensland University of Technology, 60 Musk Ave, Kelvin Grove Campus, Brisbane, QLD 4059, Australia

E-mail: yin.xiao@qut.edu.au

*Contributed equally

Key words: human periodontal ligament cells, osteogenic differentiation, tricalcium phosphate, demineralized bone matrix activity and the osteogenic differentiation of the hPDLCs cultured on the $\beta$-TCP ceramics and DBM were examined in both the growth culture medium and osteogenic culture medium. Specific osteogenic differentiation markers were examined using reverse transcription-quantitative polymerase chain reaction (RT-qPCR). SEM images revealed that the cells on the $\beta$-TCP were spindle-shaped and much more spread out compared with the cells on the DBM surfaces. There were no significant differences observed in cell proliferation between the $\beta$-TCP ceramics and the DBM scaffolds. Compared with the cells that were cultured on $\beta$-TCP ceramics, the ALP activity, as well as the Runx2 and osteocalcin (OCN) mRNA levels in the hPDLCs cultured on DBM were significantly enhanced both in the growth culture medium and the osteogenic culture medium. The organic elements of bone may exhibit greater osteogenic differentiation effects on hPDLCs than the inorganic elements.

\section{Introduction}

Periodontitis is a globally prevalent human inflammatory disease that affects approximately $15 \%$ of the adult human population and is characterized by periodontal tissue destruction (1). Patients afflicted with periodontitis commonly exhibit clinical symptoms, such as the formation of deep periodontal pockets, extensive alveolar bone loss, the development of a necrotic or exposed cementum and inflammation of the connective tissues (2). Uncontrolled periodontal tissue destruction eventually leads to tooth migration, increased tooth mobility, tooth loss and impairments in chewing function, phonetics and esthetics. Regeneration of destroyed alveolar bone is one of the ultimate goals of periodontal therapy (1). Human periodontal ligament cells (hPDLCs) have multipotential characteristics and have been regarded as potentially useful sources for the regeneration of periodontal tissue, including bone, cementum and the periodontal ligament (2-5).

Calcium phosphate ceramics were introduced over 30 years ago as bone substitutes and have been used as bone-filling materials to provide scaffolds for cell migration and rapid bone formation due to their close chemical and crystal resemblance 
to bone minerals (6). The most widely used forms of calcium phosphate ceramics are hydroxyapatite $\left(\mathrm{HA}, \mathrm{Ca}_{10}\left[\mathrm{PO}_{4}\right]_{6}[\mathrm{OH}]_{2}\right)$ and tricalcium phosphate (TCP, $\left.\mathrm{Ca}_{3}\left[\mathrm{PO}_{4}\right]\right)$. The physicochemical properties of these two synthetic calcium phosphates vary widely (7). $\beta$-tricalcium phosphate ( $\beta$-TCP) ceramics are typical representatives that have been extensively investigated regarding their applications for bone engineering due to their osteoconductivity and bioresorbability (8-10). However, $\beta$-TCP ceramics have been reported to have limited osteoinductivity when mixed with hPDLCs (11-13). Additionally, it remains controversial as to whether $\beta$-TCP possesses intrinsic osteoinductive activity.

Demineralized bone matrix (DBM) is an osteoconductive and osteoinductive commercial biomaterial and an approved medical device for use in bone defects that has a long track record of clinical uses in diverse forms (14). Unlike synthetic materials and mineralized allografts, DBM is well known for being osteoinductive and capable of stimulating bone formation in both heterotopic and orthotopic implant sites due to its content of osteogenic factors, including bone morphogenetic proteins (BMPs) and other osteogenic non-collagenous proteins (15). Numerous studies have demonstrated the potent effects of DBM on the differentiation of osteoprogenitor cells into osteoblasts (14). However, only a few studies have documented the effects of DBM on the proliferation and osteogenic differentiation of hPDLCs in periodontal regeneration $(16,17)$.

Thus, the objective of the present study was to examine the effects of $\beta$-TCP ceramics and DBM on the proliferation and osteogenic differentiation of hPDLCs.

\section{Materials and methods}

Cell culture. hPDLCs were obtained from healthy premolar teeth that were extracted for orthodontic reasons from subjects under the age of 20 years. The experimental protocol was approved by the Ethics Committee of Sun Yat-sen University, Guangzhou, China and informed consent was obtained from all subjects. The hPDLCs were isolated from fresh periodontal ligament (PDL) tissues using the protocols described in our previous study (18). Briefly, PDL tissue was removed from the middle-third of the root using a sterile scalpel and then dissected into small sections and soaked in fresh Dulbecco's modified Eagle's medium (DMEM/high glucose; HyClone, Beijing, China) containing $20 \%$ fetal bovine serum (FBS; BioInd, Kibbutz Beit Haemek, Israel) and 2\% (v/v) penicillin/streptomycin (Invitrogen, Grand Island, NY, USA). The cells that migrated out of the tissue samples were cultured at $37^{\circ} \mathrm{C}$ in a humidified atmosphere of $5 \% \mathrm{CO}_{2}$. Cells at passages 3-5 were used in the subsequent experiments.

Scaffold processing and cell seeding. The porous $\beta$-TCP ceramics were obtained from the National Engineering Research Center for Biomaterials (Chengdu, China). The mean pore sizes ranged from 200 to $500 \mu \mathrm{m}$, and the total porosity was $>60 \%$ (Fig. 1A). The ceramics were machined into cubes with dimensions of $5 \times 5 \times 5 \mathrm{~mm}$. Prior to use, all scaffolds were sterilized for $15 \mathrm{~min}\left(121^{\circ} \mathrm{C}, 15\right.$ bar pressure $)$ by autoclaving.

DBM collagen scaffolds were prepared from the spongy bone of humans. The spongy bone was provided by Osteolink Biomaterials Inc. (Wuhan, China). The demineralization process was similar to that described in the studies by Urist (19) and Reddi and Huggins (20), with the addition of several washing steps to remove the residual chemicals. Briefly, the spongy bone was separated and soaked in ethyl ether for $24 \mathrm{~h}$ to remove the fatty components. Subsequently, 0.6 M $\mathrm{HCl}$ was used to demineralize the spongy bone, and this step was followed by a complete washing in phosphate-buffered saline (PBS) and subsequent freeze-drying. Prior to use, all the samples were cut into $5 \times 5 \times 5-\mathrm{mm}$ cube sizes and sterilized by Co60 radiation (Fig. 1B).

Prior to cell seeding, all scaffolds were pre-wet and incubated in DMEM supplemented with 10\% FBS and $2 \%$ penicillin/streptomycin for $4 \mathrm{~h}$. Subsequently, the hPDLCs were seeded on the scaffolds at two different densities. The cell-scaffold complexes were transferred onto 24-well plates.

For the cell proliferation assay, $20 \mu 1$ of cell suspension $\left(1 \times 10^{5}\right.$ cells $\left./ \mathrm{ml}\right)$ was used to seed the cells on each scaffold. The cell-scaffold complexes were then cultured in DMEM growth culture medium supplemented with $10 \%$ FBS and $2 \%$ penicillin/streptomycin.

For the cell differentiation assay, $100 \mu 1$ of cell suspension $\left(3 \times 10^{6}\right.$ cells $\left./ \mathrm{ml}\right)$ was seeded on each scaffold. The cell-scaffold complexes were then cultured in growth medium or osteogenic culture medium containing $10 \mathrm{mM} \beta$-glycerophosphate ( $\beta$-GP), $10^{-8} \mathrm{M}$ dexamethasone (Dex), $50 \mu \mathrm{g} / \mathrm{ml}$ L-ascorbic acid and $50 \mu \mathrm{g} / \mathrm{ml}$ gentamycin. The culture medium was refreshed every 3 days.

Scanning electron microscopy (SEM) analysis. On day 3 after cell seeding, the cell-scaffold complexes were washed in PBS twice and fixed in $2.5 \%$ glutaraldehyde for $4 \mathrm{~h}$. Then, the samples were dehydrated in a graded series of ethanol and air-dried in tetramethylsilane (Merck, Darmstadt, Germany). After gold sputtering, the specimens were examined under a scanning electron microscope (JSM 5600; JEOL, Tokyo, Japan) at $15 \mathrm{kV}$.

Cell proliferation assay. The proliferation of the hPDLCs cultured on the scaffolds was measured in the growth culture medium using the Cell Counting kit-8 (CCK-8; Beyotime, Shanghai, China). In brief, the hPDLCs on the scaffolds were cultured in growth medium for $1,3,5,7,9$ or 11 days with 4 repeats for each group. The cell-scaffolds complexes were cut into small sections, and the cells were removed from the scaffolds by trypsinization. Ten microliters of CCK-8 solution were placed into each well. The absorbance of the supernatant was read using an enzyme-labeled meter (Infinite 200; Tecan, Grödig, Austria) at $490 \mathrm{~nm}$. A standard curve relating cell number to absorbance was established to determine the cell numbers. The scaffolds with the cells in the same media were used as the negative controls. The monolayer cultures of hPDLCs in the microplates served as the positive controls.

Alkaline phosphatase (ALP) activity. Following 3, 7, 14, 21 and 28 days of culture, ALP activity was measured using an ALP activity assay kit (Nanjing Jiancheng Bioengineering Institute, Nanjing, China) following the manufacturer's instructions. All analyses were performed for 3 separate experiments. Briefly, the cell-scaffold complexes were cut into small sections, and the proteins from the cell-scaffold complexes were extracted by 

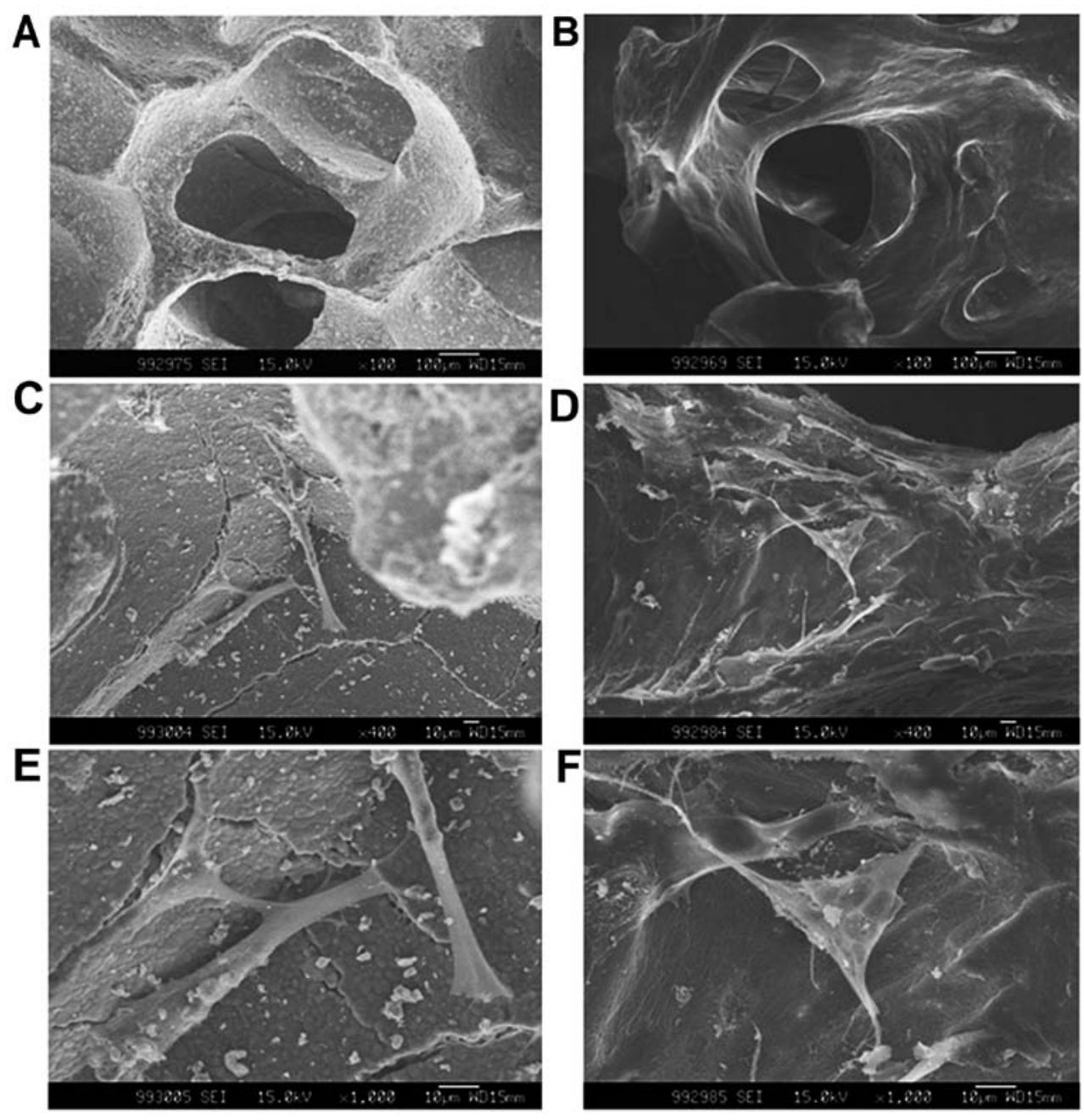

Figure 1. Scanning electron microscopy (SEM) observations of human periodontal ligament cell (hPDLC) growth within the $\beta$-tricalcium phosphate ( $\beta$-TCP) and demineralized bone matrix (DBM) scaffolds. SEM images showing the inner morphologies of the (A) $\beta$-TCP and (B) DBM. Images taken on day 3 showing that the cells had successfully adhered to the (C and E) $\beta$-TCP and the (D and F) DBM scaffolds. The cells cultured on the $\beta$-TCP appeared spindle-shaped, and those within the DBM were triangle-shaped.

Table I. Primer sequences used for RT-qPCR.

\begin{tabular}{llc}
\hline Genes & \multicolumn{1}{c}{ Primers } & $\begin{array}{l}\text { Size } \\
\text { (bp) }\end{array}$ \\
\hline Runx2 & F: CCAACCCACGAATGCACTATC & 91 \\
& R: TAGTGAGTGGTGGCGGACATAC & \\
OCN & F: CACTCCTCGCCCTATTGGC & 148 \\
& R: GCCTGGGTCTCTTCACTACCT & \\
GAPDH & F: CATGTTCCAATATGATTCCACC & 88 \\
& R: GATGGGATTTCCATTGATGAC &
\end{tabular}

F, forward; R, reverse; OCN, osteocalcin.

the addition of a cell lysis buffer containing $0.1 \%$ Triton X-100 to the samples. Aliquots (50 $\mu 1$ in each well) of these supernatants were placed into 24 -well plates containing $50 \mu \mathrm{l}$ of an ALP substrate solution $\left(2 \mathrm{mM} \mathrm{MgCl}_{2}\right.$ and $16 \mathrm{mM}$ p-nitrophenyl phosphate). Following incubation at $37^{\circ} \mathrm{C}$ for $30 \mathrm{~min}$, the reac- tion was terminated by the addition of $50 \mu \mathrm{l}$ of $0.2 \mathrm{M} \mathrm{NaOH}$, and the liberated p-nitrophenol was measured on a plate reader at $520 \mathrm{~nm}$.

Reverse transcription-quantitative polymerase chain reaction ( $R T-q P C R$ ). The expression levels of Runx 2 and osteocalcin (OCN) were confirmed by RT-qPCR on day 21 . Total RNA from the cells was prepared from the crushed sections of each scaffold $(n=3)$ and then harvested using TRIzol reagent (Invitrogen, Carlsbad, CA, USA). The total RNA was used as a template for the synthesis of cDNA with oligo(dT) and RevertAid $^{\mathrm{TM}}$ M-MuLV reverse transcriptase (MBI/Fermentas, Burlington, ON, Canada). The following PCR amplification reaction employed Taq polymerase and specific primers. Each PCR was duplicated with the same total RNA. The relative gene expression levels of Runx 2 and OCN were normalized to the housekeeping gene, glyceraldehyde 3-phosphate dehydrogenase (GAPDH). The primers for the selected genes are listed in Table I.

Statistical analysis. All experiments were performed 3 or 4 times, and each treatment was conducted in triplicate. The 


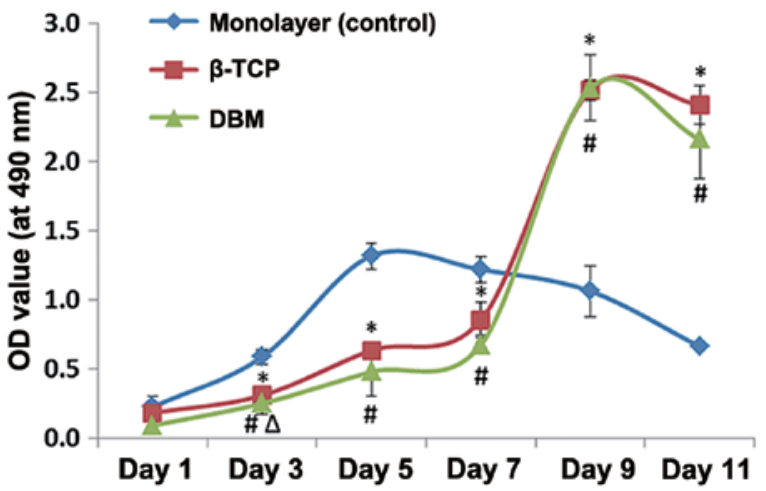

Figure 2. Proliferation of human periodontal ligament cells (hPDLCs) cultured on $\beta$-tricalcium phosphate ( $\beta$-TCP) and demineralized bone matrix (DBM) scaffolds. The rates of hPDLC proliferation in the $\beta$-TCP were slightly greater than those in the DBM from days 1 to 11 , but these differences were not significant with the exception of day $3 .{ }^{*} \mathrm{P}<0.05, \beta$-TCP compared with the control; " $\mathrm{P}<0.05$, DBM compared with the controls, ${ }^{\Delta} \mathrm{P}<0.05$, DBM compared with $\beta$-TCP.

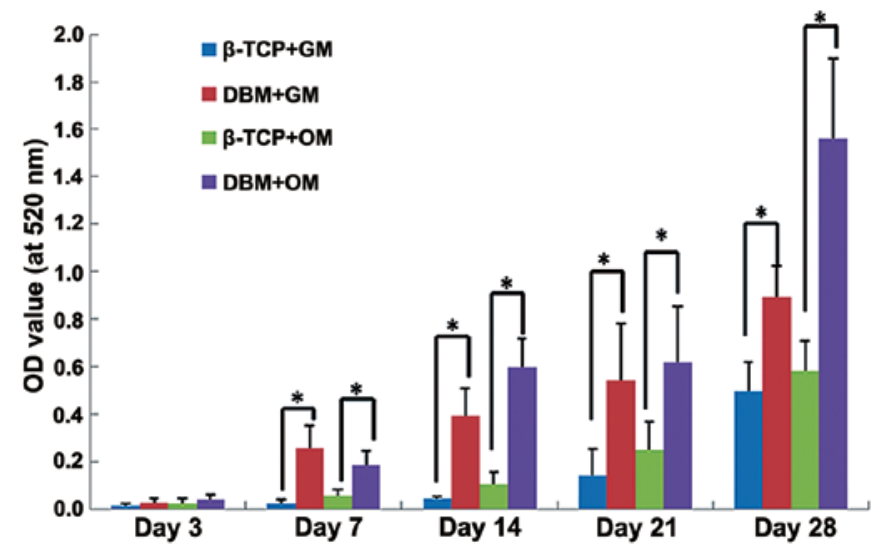

Figure 3. Alkaline phosphatase (ALP) activity of the human periodontal ligament cells (hPDLCs) that were cultured on the $\beta$-tricalcium phosphate $(\beta-\mathrm{TCP})$ and demineralized bone matrix (DBM) scaffolds. In both the growth culture medium (GM) and the osteogenic culture medium (OM), the ALP activity of the cells that were cultured on the DBM was significantly increased compared with that of the cells cultured on $\beta$-TCP at all time points with the exception of day 3 . ${ }^{*} \mathrm{P}<0.05$, compared with the controls.

means (Ms) and standard deviations (SDs) were calculated, and the statistical significances of the differences between groups were examined with one-way ANOVA followed by the least significant difference (LSD) test. The SPSS 17.0 program was employed for all statistical analyses, and differences were considered significant when the P-value was $<0.05$.

\section{Results}

Scanning electron microscopy (SEM). On day 3 after cell seeding, the hPDLCs had successfully adhered to both scaffolds. The cell morphologies of the hPDLCs on the $\beta$-TCP ceramics and DBM surfaces exhibited some differences. The cells cultured on the $\beta$-TCP surfaces appeared spindle-shaped and much more spread out than the cells cultured on the DBM surfaces, and the hPDLCs within the DBM exhibited a triangular shape (Fig. 1C-F).

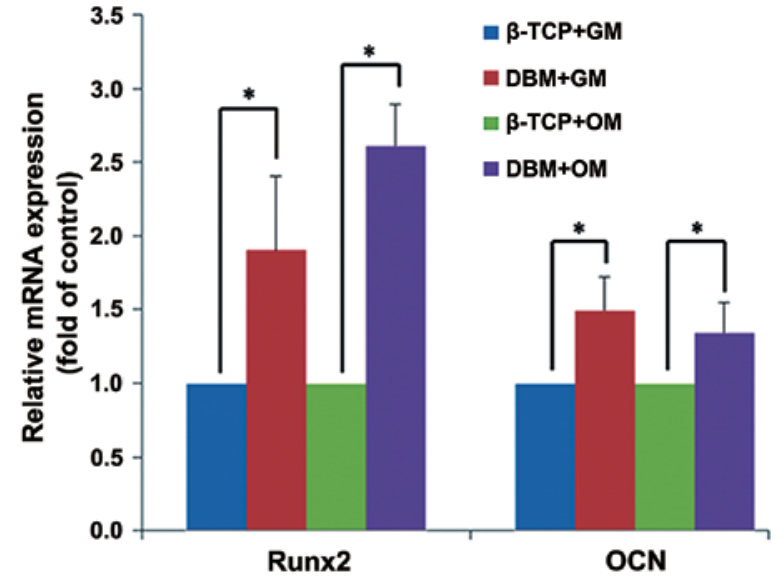

Figure 4. RT-qPCR of osteogenic differentiation markers in human periodontal ligament cells (hPDLCs). After 21 days of culture, the hPDLCs within the demineralized bone matrix (DBM) exhibited significantly greater levels of Runx2 and osteocalcin (OCN) in both the growth medium (GM) and the osteogenic culture medium (OM) compared with those in the $\beta$-TCP. ${ }^{*} \mathrm{P}<0.05$, compared with the control.

Cell proliferation. Compared with the monolayer group (positive control), the cell proliferation levels in the scaffolds were significantly inhibited from days 3 to 7 , but significantly elevated from days 9 to $11(\mathrm{P}<0.05)$. A comparison of the growth of the cells in the scaffolds revealed that the cell numbers in the DBM from days 1 to 11 were lower than those in the $\beta$-TCP ceramics. However, the difference in cell proliferation between these 2 groups was not statistically significant $(\mathrm{P}>0.05)$ with the exception of day 3 (Fig. 2).

ALP activity. In both the growth culture medium and the osteogenic culture medium, the ALP activity gradually increased from days 3 to 28 . The hPDLCs cultured in the osteogenic medium exhibited greater ALP activity than did those (same scaffoled different medium) cultured in the growth medium. The ALP activity of the hPDLCs cultured on the DBM was significantly greater than that of the cells cultured on $\beta$-TCP at all time points in both the growth medium and the osteogenic culture medium (Fig. 3).

Expression of osteogenic differentiation genes. After 21 days of culture, the hPDLCs cultured on the DBM exhibited significantly greater levels of Runx 2 and OCN both in the growth medium and the osteogenic culture medium $(\mathrm{P}<0.05)$ compared with those cultured on $\beta$-TCP. The mRNA expression of Runx 2 was increased in the presence of the osteogenic inducers to a greater extent than in the absence of the osteogenic inducers. Runx 2 expression was induced to a greater extent with osteogenic inducers only with DBM. It was not as high with $\beta$-TCP with osteogenic inducers. The mRNA expression of OCN exhibited no detectable difference between the different culture media (Fig. 4).

\section{Discussion}

Scaffolding materials should be biocompatible and bioactive to allow specific cells to attach, proliferate, and differentiate on the scaffolding materials to enable tissue repair and regenera- 
tion (4-8). $\beta$-TCP is a porous bioceramic material with biological properties that include non-reactivity and resorbability. $\beta$-TCP can serve as a scaffold for bone regeneration as it is progressively degraded and replaced by bone. Due to its osteoconductivity and bone replacement capability, $\beta$-TCP is highly promising for use in numerous dental and craniofacial procedures, including the reconstruction of frontal sinus cavities, the augmentation of craniofacial skeletal defects and the repair of periodontal tooth and bone defects (21-24). DBM products were clinically introduced in 1991 and have since served as effective osteoconductive scaffolds $(25,26)$. The osteoinductivity of DBM can be attributed to a series of low-molecular-weight glycoproteins that include the BMPs. The decalcification of cortical bone exposes these osteoinductive growth factors that are buried within the mineralized matrix and thereby enhances the bone formation process (27). DBM has a number of additional advantages that make it an attractive bone graft alternative. DBM is cost-effective and readily available from tissue banks. The demineralization process destroys the antigenic materials in the bone, which makes DBM less immunogenic than mineralized allografts $(25,28)$.

The present study investigated the effects of $\beta$-TCP ceramics and DBM, which are commercially available bone graft substitutes, on the proliferation and osteogenic differentiation of hPDLCs. A CCK- 8 assay revealed that both the $\beta$-TCP scaffolds and DBM were able to promote the late, but not the early proliferation of hPDLCs. SEM observations revealed that the hPDLCs attached to the surfaces of the $\beta$-TCP scaffolds and the DBM by spreading themselves out. Such responses are indicative of good cytocompatibility and the close interactions of the scaffolds with the hPDLCs. The cells on the $\beta$-TCP surfaces appeared spindle-shaped and much more spread out than those on the DBM surfaces and the hPDLCs within the DBM became triangle-shaped. These different cellular morphologies may be associated with the differentiation of the hPDLCs cultured on DBM toward the osteogenic lineage.

ALP is an early biomarker of osteogenic differentiation and plays a key role in bone mineralization through the initiation and/or promotion of the formation of hydroxyapatite crystals in the matrix vesicles of osteoblasts (29). The present study revealed that the hPDLCs cultured on the DBM exhibited greater ALP activity than did the cells cultured on the $\beta$-TCP scaffolds. These results may be related to the different chemical compositions of the scaffolds. $\beta$-TCP is biodegradable and can release various concentrations of calcium and phosphate ions into the culture media or body fluids (30-32). In a previous study, the concentrations of calcium and inorganic phosphate ions released from $\beta$-TCP ceramics after 3 days of culture were 1.76 and $0.96 \mathrm{mmol} / 1$, respectively (33). In a previous study of ours, we demonstrated that this release of free calcium and inorganic phosphate ions significantly reduces the ALP activities of hPDLCs (18). However, the DBM was prepared by acid extraction from human bone sources and thus retained type I collagen, other proteins and BMPs. BMPs are obviously able to stimulate ALP activity $(34,35)$.

The differentiation of hPDLCs is one of the key processes of bone regeneration. The mRNA expression levels of Runx 2 and OCN were selected as markers of the osteogenic phenotype. $\beta$-TCP ceramics possess osteoconductive properties, but they do not have intrinsic osteoinductive capacities. DBM has been shown to have osteoconductive and osteoinductive properties (36). In the present study, compared to the $\beta$-TCP ceramics, the DBM scaffolds upregulated the expression levels of these genes in both the growth and osteogenic culture media on day 21. These results are consistent with those of a previous study by Kasten et al (37) who reported that DBM increased OCN gene expression in human bone marrow stromal cells. Runx 2 has been identified as a 'master gene' in the control of osteogenic differentiation $(38,39)$. Thus, the significant upregulation of Runx 2 gene expression led to elevated mRNA expression levels of OCN in the hPDLCs within the DBM. Runx2 is an early-stage transcription factor that activates osteoblastic differentiation $(36,37)$, and its gene expression was significantly increased in the DBM substrates (1.9- and 2.6-fold in the growth and osteogenic media, respectively). OCN is a late-stage osteogenic differentiation marker and is synthesized only by mature osteoblasts, odontoblasts and cementoblasts $(38,39)$. The results from RT-qPCR revealed that OCN gene expression was slightly increased in the DBM substrates (1.5- and 1.3-fold in the growth and osteogenic media, respectively). Thus, we conclude that DBM promoted the osteogenic differentiation of hPDLCs.

$\beta$-TCP is a biodegradable inorganic bone substitute that can release varying amounts of calcium and phosphate ions into culture media or body fluids $(30,31,40)$. These releases of free calcium or phosphate ions significantly affect the proliferation and osteogenic differentiation of hPDLCs (18). DBM is an allogenous material and thus contains bone morphogenic and matrix proteins that ceramic materials do not (14). The results of the present study may be due to the sum of the effects of the dissolved ions and matrix proteins and the direct effects of the scaffold architecture and surface chemistry. Notably, the chemical composition, surface topography, surface roughness and other characteristics of scaffolds have been reported to affect cell activities, such as adhesion, proliferation and differentiation (41).

In conclusion, the results of the present study revealed that in addition to the induction of cell proliferation in the absence of an osteogenic inducer, DBM scaffolds exhibited greater effects on the osteogenic differentiation of hPDLCs than did porous $\beta$-TCP ceramics. The organic elements of bone have more prominent effects on the osteogenic differentiation of hPDLCs than do the inorganic bone elements. It may thus be possible to develop novel periodontal tissue engineering scaffolds by combining the organic (e.g., collagen, other proteins and BMPs) and inorganic elements (e.g., calcium and phosphate ions) of bone in various concentrations and ratios.

\section{Acknowledgements}

This study was supported by the Guangdong Natural Science Foundation (grant no. S2012040007041).

\section{References}

1. Hughes FJ, Ghuman M and Talal A: Periodontal regeneration: a challenge for the tissue engineer? Proc Inst Mech Eng H 224: 1345-1358, 2010

2. Ishikawa I, Iwata T, Washio K, Okano T, Nagasawa T, Iwasaki K and Ando T: Cell sheet engineering and other novel cell-based approaches to periodontal regeneration. Periodontol 2000 51: 220-238, 2009

3. Lin NH, Gronthos S and Mark Bartold P: Stem cells and future periodontal regeneration. Periodontol 2000 51: 239-251, 2009. 
4. Bartold PM, McCulloch CA, Narayanan AS and Pitaru S: Tissue engineering: a new paradigm for periodontal regeneration based on molecular and cell biology. Periodontol 2000 24: 253-269, 2000.

5. Taba M Jr, Jin Q, Sugai JV and Giannobile WV: Current concepts in periodontal bioengineering. Orthod Craniofac Res 8: 292-302, 2005.

6. Wagoner Johnson AJ and Herschler BA: A review of the mechanical behavior of $\mathrm{CaP}$ and $\mathrm{CaP} /$ polymer composites for applications in bone replacement and repair. Acta Biomater 7: 16-30, 2011.

7. El-Ghannam A: Bone reconstruction: from bioceramics to tissue engineering. Expert Rev Med Devices 2: 87-101, 2005.

8. Kamitakahara M, Ohtsuki C and Miyazaki T: Review paper: behavior of ceramic biomaterials derived from tricalcium phosphate in physiological condition. J Biomater Appl 23: 197-212, 2008.

9. LeGeros RZ: Properties of osteoconductive biomaterials: calcium phosphates. Clin Orthop Relat Res 395: 81-98, 2002.

10. Nandi SK, Roy S, Mukherjee P, Kundu B, De DK and Basu D: Orthopaedic applications of bone graft \& graft substitutes: a review. Indian J Med Res 132: 15-30, 2010.

11. Iwata T, Yamato M, Tsuchioka H, Takagi R, Mukobata S, Washio K, Okano T and Ishikawa I: Periodontal regeneration with multi-layered periodontal ligament-derived cell sheets in a canine model. Biomaterials 30: 2716-2723, 2009.

12. Anzai J, Kitamura M, Nozaki T, Nagayasu T, Terashima A, Asano $T$ and Murakami S: Effects of concomitant use of fibroblast growth factor (FGF)-2 with beta-tricalcium phosphate $(\beta$-TCP) on the beagle dog 1-wall periodontal defect model. Biochem Biophys Res Commun 403: 345-350, 2010.

13. Xia L, Zhang Z, Chen L, Zhang W, Zeng D, Zhang X, Chang J and Jiang $X$ : Proliferation and osteogenic differentiation of human periodontal ligament cells on akermanite and $\beta$-TCP bioceramics. Eur Cell Mater 22: 68-82, 2011.

14. Gruskin E, Doll BA, Futrell FW, Schmitz JP and Hollinger JO Demineralized bone matrix in bone repair: history and use. Adv Drug Deliv Rev 64: 1063-1077, 2012.

15. Mauney JR, Jaquiery C, Volloch V, Heberer M, Martin I and Kaplan DL: In vitro and in vivo evaluation of differentially demineralized cancellous bone scaffolds combined with human bone marrow stromal cells for tissue engineering. Biomaterials 26: 3173-3185, 2005

16. Miron RJ, Bosshardt DD, Laugisch O, Dard M, Gemperli AC, Buser D, Gruber R and Sculean A: In vitro evaluation of demineralized freeze-dried bone allograft in combination with enamel matrix derivative. J Periodontol 84: 1646-1654, 2013.

17. Papadopoulos CE, Dereka XE, Vavouraki EN and Vrotsos IA In vitro evaluation of the mitogenic effect of platelet-derived growth factor-BB on human periodontal ligament cells cultured with various bone allografts. J Periodontol 74: 451-457, 2003.

18. An S, Ling J, Gao Y and Xiao Y: Effects of varied ionic calcium and phosphate on the proliferation, osteogenic differentiation and mineralization of human periodontal ligament cells in vitro. J Periodont Res 47: 374-382, 2012.

19. Urist MR: Bone: formation by autoinduction. 1965. Clin Orthop Relat Res 395: 4-10, 2002.

20. Reddi AH and Huggins C: Biochemical sequences in the transformation of normal fibroblasts in adolescent rats. Proc Natl Acad Sci USA 69: 1601-1605, 1972.

21. Shayegan A, Petein M and Vanden Abbeele A: The use of betatricalcium phosphate, white MTA, white Portland cement and calcium hydroxide for direct pulp capping of primary pig teeth. Dent Traumatol 25: 413-419, 2009.

22. Elahi MM, Vanduzer S, Spears J, Gibson J and Mitra A: Frontal sinus obliteration with beta-tricalcium phosphate. J Craniofac Surg 15: 967-970, 2004

23. Mahr MA, Bartley GB, Bite U, Clay RP, Kasperbauer JL and Holmes JM: Norian craniofacial repair system bone cement for the repair of craniofacial skeletal defects. Ophthal Plast Reconstr Surg 16: 393-398, 2000.
24. Dori F, Arweiler N, Gera I and Sculean A: Clinical evaluation of an enamel matrix protein derivative combined with either a natural bone mineral or beta-tricalcium phosphate. J Periodontol 76: 2236-2243, 2005.

25. Sandhu HS, Khan SN, Suh DY and Boden SD: Demineralized bone matrix, bone morphogenetic proteins, and animal models of spine fusion: an overview. Eur Spine J 10 (Suppl 2): S122-S131, 2001.

26. Martin GJ Jr, Boden SD, Titus L and Scarborough NL: New formulations of demineralized bone matrix as a more effective graft alternative in experimental posterolateral lumbar spine arthrodesis. Spine 24: 637-645, 1999.

27. Urist MR, Mikulski A and Lietze A: Solubilized and insolubilized bone morphogenetic protein. Proc Natl Acad Sci USA 76: 1828-1832, 1979.

28. Guizzardi S, Di Silvestre M, Scandroglio R, Ruggeri A and Savini R: Implants of heterologous demineralized bone matrix for induction of posterior spinal fusion in rats. Spine 17: 701-707, 1992.

29. Orimo H and Shimada T: The role of tissue-nonspecific alkaline phosphatase in the phosphate-induced activation of alkaline phosphatase and mineralization in SaOS-2 human osteoblastlike cells. Mol Cell Biochem 315: 51-60, 2008.

30. Puleo DA and Nanci A: Understanding and controlling the boneimplant interface (Review). Biomaterials 20: 2311-2321, 1999.

31. Bernstein A, Nöbel D, Mayr HO, Berger G, Gildenhaar R and Brandt J: Histological and histomorphometric investigations on bone integration of rapidly resorbable calcium phosphate ceramics. J Biomed Mater Res B Appl Biomater 84: 452-462, 2008.

32. Langstaff S, Sayer M, Smith TJ and Pugh SM: Resorbable bioceramics based on stabilized calcium phosphates. Part II: evaluation of biological response. Biomaterials 22: 135-150, 2001.

33. Ni S, Chang J, Chou L and Zhai W: Comparison of osteoblastlike cell responses to calcium silicate and tricalcium phosphate ceramics in vitro. J Biomed Mater Res B Appl Biomater 80: 174-183, 2007.

34. Zimmermann G and Moghaddam A: Allograft bone matrix versus synthetic bone graft substitutes. Injury 42 (Suppl 2): S16-S21, 2011

35. Hu Z, Peel SA, Lindholm TC, Sàndor GK, Clokie CM and Su Y: Osteoinductivity of partially purified bovine, ostrich and emu bone morphogenetic proteins in vitro. J Biomed Mater Res A 98: 473-477, 2011.

36. Katz JM, Nataraj C, Jaw R, Deigl E and Bursac P: Demineralized bone matrix as an osteoinductive biomaterial and in vitro predictors of its biological potential. J Biomed Mater Res B Appl Biomater 89: 127-134, 2009.

37. Kasten P, Luginbühl R, van Griensven M, Barkhausen T, Krettek C, Bohner M and Bosch U: Comparison of human bone marrow stromal cells seeded on calcium-deficient hydroxyapatite, beta-tricalcium phosphate and demineralized bone matrix. Biomaterials 24: 2593-2603, 2003.

38. Jensen ED, Gopalakrishnan R and Westendorf JJ: Regulation of gene expression in osteoblasts. Biofactors 36: 25-32, 2010.

39. Komori T: Regulation of bone development and extracellular matrix protein genes by RUNX2. Cell Tissue Res 339: 189-195, 2010.

40. Burg KJ, Porter S and Kellam JF: Biomaterial developments for bone tissue engineering. Biomaterials 21: 2347-2359, 2000.

41. Lee J, Cuddihy MJ and Kotov NA: Three-dimensional cell culture matrices: state of the art. Tissue Eng Part B Rev 14: 61-86, 2008. 